\title{
Getting funded. Multi-level network of physicists in Italy
}

\author{
Elisa Bellotti* \\ The Mitchell Centre for Social Network Analysis, and Sustainable Consumption Institute, University of Manchester, United Kingdom
}

\section{A R T I C L E I N F O}

\section{Keywords:}

Sociology of science

Multi-level networks

Bipartite networks

Meso-sociology

Fish/pond

Research funding

\begin{abstract}
A B S T R A C T
Much of the work in the sociology of science observes scientific communities from a micro perspective, focusing on interactions in laboratories in order to uncover the impact of social and cultural norms in the everyday production of scientific results. Other studies approach the topic from a macro perspective, analysing scientific organizations and the reciprocal influence they have with wider society, or uncovering the invisible colleges that become apparent through the analysis of co-authorship and citations' patterns. Less attention has been paid to the meso level of interaction within and between scientists and the institutions they work in. This paper extends the structural approach of Lazega et al. (2008. Catching up with big fish in the big pond? Multi-level network analysis through linked design. Social Networks 30, 157-176) and analyses the local system of public funding to physics in Italy using bipartite networks. Data cover 10 years of funding of Projects of National Interest (Prin) from the Italian Ministry of University and Research. The micro level (collaborations between scientists), macro level (collaborations between institutions) and meso level (the combination of network measures at a micro and macro level) of interactions are independently analysed, and results are used to model the total amount of money physicists have received over the 10 years against the variables that meaningfully describe the network structure of collaborations. Results show that in order to be successfully funded what counts more than being a big fish (a scientist with a lot of connections) working in a big pond (a large University), is being in a brokerage position interacting over the years with different research groups.
\end{abstract}

(C) 2011 Elsevier B.V. All rights reserved.

\section{Introduction}

The production of scientific knowledge is a complex mechanism that involves several agencies, such as funding bodies, universities, scientists, and laboratories for experimental research. It is also a process of different phases, such as selection of research areas, recruitment of research groups, competition for funding, organization of research work, publication of results and dissemination of findings both in a scientific community and to the wider public. All the steps required to produce and validate science can be seen as systems of interconnections between different actors at different levels, engaging in social interactions where the goal is to make research possible, and to gain scientific prestige both for individuals and for organizations.

The tradition of studies in sociology of science has been focused on disentangling these processes in order to describe and explain

\footnotetext{
is Data presented in this article are part of a Prin project "Campi di produzione del sapere a confronto: strutture, pratiche e attori nella fisica e nella filosofia", funded in 2005 by the Italian Ministry of University and Research.

* Correspondence address: Arthur Lewis Building, Bridgeford Street, Manchester M13 9PL, United Kingdom. Tel.: +44 01612752921.

E-mail address: Elisa.Bellotti@manchester.ac.uk
}

the social factors that play a role both in the life of scientists and in the definition of what is required to be considered science. Much work has been dedicated to exploring the social elements that shape the scientific production of knowledge, showing how the process of defining objectivity is not only subjected to empirical evidence and logic consistency, but also to social and cultural factors. Within the process of validation and recognition of science, power and competition relationships interlock with collaboration and discussion in order to achieve a collective definition of scientific knowledge.

Sociology of science studies the process of constitution of institutional apparatuses in charge of organizing the production of science. The importance of knowing how these apparatuses work is crucial for any scientific discipline: while some of them are still characterized by a relative small scale of organization, some others, like physics, are today dominated by what has been called big science (de Solla Price, 1963): these scientific fields require big research groups, massive technological instruments, and large laboratories where experiments are centralized and funded by national governments, who commit to long term investments. This means that big science cannot be done entirely at a national level anymore (as it was the case until the Second World War) and that funding efforts are concentrated to few large experiments and laboratories (like Cern in Ginevra or Slac in S. Francisco for particle physics). 
The international organization of big science does not entirely wash away national differences: while the job market of scientific careers is more internationalised in English speaking countries, other countries' systems of recruitment are still nationally based. This is the case of Italy, where the academic system of recruitment is centralized around the Ministry of University and Research (Miur) and the vast majority of scientists are Italian. Here mechanisms are localised and scientific communities are more easily bounded, but they still need to be empirically examined, as it is not always immediately evident who belongs to a community, who is peripheral, who is not part of it, and how connected such a community is. Each academic sector in Italy is organized around sub-disciplines; every sub-discipline enrols scientists via national competitions organized by Miur, and successful candidates are subsequently appointed by Universities according to departments' needs. While the subdisciplines all together and their distinctions might be useful to identify a scientific community and its subgroups, different strands of research can be found in sub-disciplines; also, interdisciplinary collaborations cut across disciplinary boundaries, making the borders of sub-disciplines and the whole field of science permeable; finally, as in the case of Italian physics, Miur only controls academic careers, but other independent institutions, like the National Institutes for Nuclear Physics (Infn), and for Material Physics (Infm), also contribute to scientific research with their own employed scientists.

Institutions impact over science at a macro level. They provide the infrastructure, the organizational and the intellectual environment for research: universities, departments, laboratories and research centres exchange people, ideas and technologies, collaborate for production and dissemination of results, and produce organizational cultures that define their goals and their practices. Scientists live and work in this environment, and interact within the institutional frame that shapes their possibilities and constrains. At the same time, at a micro, individual level, scientists develop several kinds of relationships with people they meet along their career: friendship, advice exchanges, rivalry, collaborations, conflicts and mentorships are social relations that can play an important role in facilitating or hampering the production of science in terms of diffusion of knowledge and validation of results. An interesting attempt to study the way in which these different levels intersect is represented by the structural approach of multilevel networks (Breiger, 1974; Fararo and Doreian, 1984; Hedström et al., 2000; Lazega et al., 2008). Here, the macro level of institutional and organizational linkages is connected to the micro level of personal relationship via a meso level of affiliations: in other words, the structural approach is able to connect the organizational structure with the web of personal interactions, and to observe how the two interconnected levels affect the performances of both institutions and individuals.

This paper follows the structural approach in order to reconstruct and analyse the Italian national system of public funding in the field of physics. Data presented here are only a small part of a wider research project on the production of knowledge in physics in Italy (Bellotti et al., 2008; Bellotti, 2011), and they focus on the Research Projects of National Interests (Prin) funded in Italy by Miur in the area of physics from 1997 to 2006. This is not the only line of funding available in Italy: other sources of money are for example Infn and Infm which provide the major part of funding for research in terms of the Italian participation to the big international experiments (Volontè, 2008). However, Prin is an important line of funding as it is mainly used to create temporary research positions (Bellotti, 2008), and because it is one of the criteria of evaluation of scientists' careers in Italy. Moreover, it illustrates some interesting peculiarities of the Italian academic system.

Historically, the fundamental research in physics in Italy has been lead by Infn, an institution created in 1951 with the specific intention to subtract the decisional power and the control over funding in the area of physics from the local powers of academic departments on one side, and the bureaucracy of Ministry of University and Research on the other side. Infn was funded via the Cnrn, the National Committee for Nuclear Research, created the following year by the Ministry of Industry and Trade (it became the National Committee of Nuclear Energy, Cnen, in 1960): the fact that the institution was created and funded by the Ministry of Industry and Trade, rather than the Ministry of University and Research, highlights the political and economic interests in supporting Italian research in physics in order to keep pace with the international competition over nuclear energy, but also signals the marginal role of Universities in the initial participation of Italy to the emerging international big science (Ippolito and Simen, 1974; Volontè, 2008). While Infn rapidly became the main institutional actor in Italian physics (followed by Infm, a twin institution created in the ' 80 s for material physics) in terms of control over the system of research funding, the scientific careers of physicists are still mainly controlled by Universities, especially in terms of recruitment. Infn and Infm only offer research positions, therefore they appoint already trained scientists, while the training system (from undergraduate to PhD levels) is concentrated in Universities. This creates an interesting synergy between Infn and Universities, as the latter are in charge of developing future researchers. Given the fact that Prin projects are often used to create post doctoral positions, and the line of funding is only accessible by academic personnel (not by Infn researchers), it is clear the strategic importance of Prin line of funding, even if money generated by these projects is only a small part of the overall funding in physics.

Following this introduction, the second section of the paper revises the literature in sociology of science, showing how previous classic studies have focused on a micro or a macro level of observation, missing out the importance of adopting a network perspective in the study of the production of science. A structural approach has been advanced by social network scholars, who have improved the empirical validation of previous theories, and have introduced a meso level of observation which, through bipartite networks, takes into account the micro and the macro levels and the interactions between them. In the third section I introduce and contextualise the dataset, describing the competitive system of public funding to research projects in Italy, and underlining the importance of some individual variables (national coordinator, rank and sub-disciplines) in the process of obtaining money. The fourth section describes the micro, macro and meso level of collaboration to research projects, in terms of collaborations between scientists, collaborations between institutions, and the combination of the two levels. In the fifth section I hierarchically model the total amount of money received by every scientist in the 10 years under analysis against individual attributes, personal collaborations, institutional collaborations, and the categories obtained combining centrality scores at a micro level with the size of departments at a macro level. Results and limits of the present research are discussed in the final session, while conclusions highlight further research questions that have emerged from the analysis.

\section{Scientific communities and multi-level network analysis}

Much work in sociology of science is dedicated to studying the influence of social factors over the production of science. Back in the 40s Merton set up the debate insisting on a weak position of sociology of science, as only cultural aspects of the scientific job can be addressed by sociology, while the foundations of the scientific method (empirical verifiability and logic coherence) are left to epistemology of science (Merton, 1949). Departing from this classic position, subsequent scholars attempt to open the black box of scientific method and investigate the role of everyday interactions in 
the construction of the contents of science. The attention thus shifts to the analysis of controversies and conflicts that lead to changes in scientific paradigms (Kuhn, 1962). The merit of linking the production and validation of scientific products to local socio-cultural norms belongs to the Edinburgh School and the work of Barnes and Bloor (1982), as well as to Collins (1985) and the Bath school, who are interested in the processes of interactions in and through which interests, preferences and beliefs are formed, somehow independently from the structure of dispositions that scientists have according to their position in the social world. Finally, laboratory studies (Gilbert and Mulkay, 1984; Knorr-Cetina, 1992) push further the concept of scientific objects as social and cultural constructions, showing how they are technically built in laboratories and symbolically made up through literary and political discourses, whose goal is making alliances and gaining resources.

A departure from previous approaches in sociology of science can be found in the actor-network theory (ANT) developed by Latour and Callon (see for example Latour, 1987,2005). Here the concept of network is introduced, where actors can be equally people, objects (actants) and organizations. The main problem of such approach lies in the fact that ANT theory tends to be highly deterministic in terms of network constrains over actors: once an actor network is stabilized, the possibilities of actions become increasingly narrow (Whittle and Spicer, 2008). Moreover, ANT theory fails to engage with the wider literature of empirically observed networks, as ANT views social network analysis as heavily limited by the fact it accounts only for relationships between humans in informal settings (Callon, 2001; Cambrosio et al., 2004). The same critics have been advanced by Bourdieu, who accuses SNA to neglect the study of the underlying structures that shape the field of science, focusing only on "the analysis of particular linkages (between agents and institutions) and flows (of information, resources, services, etc.) through which they become visible" (Bourdieu, 2004: 114).

But these previous approaches to sociology of sciences, while criticizing SNA for the focus on concrete relationships, do themselves lack from the advantages of observing empirical networks, which are useful in understanding the reciprocal influences of local interactions over organizational structures and vice versa. Laboratory studies and ANT rely on a micro approach to the study of interactions, where the effort to regularization in an empirical repertoire is seen as local and individual strategy to gain prestige, and it is detached from the influence of the overall structure of the field of science. Bourdieu, on the other hand, abstracts the individual features (in terms of combinations of capitals required to occupy a structural position) to a macro perspective, without taking into account the level of concrete interactions (for a review of similarities and difference between SNA and Bourdieu's field theory, see Bellotti, 2011).

Also, the critics that social network analysis focuses only on human actors and on few types of relationships does not seem to be sustainable, as SNA has produced a large number of studies where actors are of different nature (scientists, institutions, conferences and workshops, articles, journals, disciplines ${ }^{1}$ ) and different kinds of relationships are mapped (friendship, mentorship, co-authorship, citations, advice, diffusion of information). But instead of being limited to the micro level of local interactional

\footnotetext{
1 While it is evident that these networks do not only take into account humans, the fundamental difference from ANT and SNA is still that in SNA there is an underlining assumption that some sort of social interaction between humans is at the basis of any kind of relationship. And it is difficult to accept ANT critics when, for example, the network presented in Cambrosio et al. (2004) is made out of reagents submitted to workshops: even if the nodes here are non human, they still entail a (group of) researcher submitting a reagent to a (group of) organizer of the workshop.
}

mechanisms, or trying to jump from the micro to the macro abstracting individual features, SNA has focused on empirical connections to test the robustness of various theories in sociology of science and to study the evolution of several disciplines (Crane, 1972; Burt, 1978/79; Lievrouw et al., 1987; Hummon and Doreian, 1989; Hummon and Carley, 1993; Liberman and Wolf, 1998).

In particular, the works of Lievrouw et al. (1987) and of Liberman and Wolf (1998) suggest two interesting elements in the study of scientific production. First, relationships between scientists cannot be reduced to co-authorship and co-citations, but involve a wider set of interactions, from competition for research funding to affiliation to different organizations. Second, they point out the importance of finding a way to mediate between the micro level of individual relationships and the macro levels of institutional exchange, where institutions can be research groups, departments, universities, specialities and disciplines, journals or even national countries. These levels are dependent to each others, as the actors are simultaneously embedded in everyday micro interactions, and in affiliations to the higher, macro level of institutions and organizations. The need for a dual approach in the study of networks, where both individuals and collectivities are taken into account, is first advanced by Breiger (1974), ${ }^{2}$ who describes the properties of two modes networks. Fararo and Doreian (1984) extend Breiger's formalism to tripartite networks, where, for example, people are embedded in groups and groups in organizations: they then generalize the conceptual basis and the matrix formalisms of bipartite graphs to tripartite networks, and produce a set of matrix equations and operations that can be applied in the study of empirical networks.

This has been done in a recent study by Lazega et al. (2008) that analyses the meso level of interaction in the production of science. In their article, Lazega et al. (2008) extend the principles of linked design (Parcel et al., 1991) to structural analysis in order to study the "duality" of social life (Breiger, 1974), where duality is represented as "multi-level networks of two systems of superposed and partially interlocked interdependencies, one inter-organizational, the other inter-individual" (Lazega et al., 2008: 160). They study the network of the élite of French cancer researchers, selected according to the number of articles published in scientific journals between 1996 and 1998, both at the individual and the organizational level. They also map several kinds of relations between individuals and between organizations, moving beyond the traditional analysis of co-citations and co-authorships.

In their analysis, they combine degree centrality measures at the level of the individual network of relationships with the ones at the level of the inter-organizational network between laboratories, and create four categories according to how central actors are (big fishes and little fishes) and how important their laboratories are in terms of potential access to resources (big ponds and little ponds). They then regress the production of knowledge, in terms of the increase in the impact factor of articles published by actors at two different point of time, against their network profiles (big fishes in big ponds, little fishes in big ponds, big fishes in little ponds and little fishes in little ponds), and point out possible strategies of the last three categories in catching up with the big fishes in big ponds. Their results show that while it is not necessary to be in a big pond (a large laboratory designated by élites as a central laboratory) in order to have a chance at catching up, the position of an organization in the inter-organizational network is still more important in terms of attaining high levels of performance than the

\footnotetext{
2 Fararo and Doreian (1984) acknowledge that the same formalization was proposed by Wilson (1982) in a paper written in the 1960s but only published later on. Wilson and Breiger arrived to the identical matrix equations of bipartite graphs.
} 
position of individual members in the network of the élite (Lazega et al., 2008: 174).

The structural approach to multilevel networks introduces an important distinction in the conceptualization of micro and macro levels. In previous research traditions of sociology of science, micro level is intended as the combination of individual attributes, or at least their symbolic interactions with others, without organizing these interactions in networks. On the other hand, macro level is the level of aggregate phenomena, where collective actions and institutions are analysed as separate from individual, assuming a reciprocal influence (of collective cultures over individuals, and of individuals' actions over collectivities) which is not empirically tested. SNA and the structural approach (like in the case of Lazega et al., 2008) consider as micro level the network of individual interactions, where attributes are only one side of the story, the other being the position individuals occupy within the network and the consequences this entails in terms of opportunities and constrains. In the same way, the macro level is considered as the network of inter and intra ties within and between organizations. A meso level links the two together via bipartite networks, accounting for interdependencies through matrix algebra.

In this paper I extend Lazega et al's method to the Italian network of collaborations to research projects in physics. The dataset consists of 10 bipartite networks of 'people by funded projects', one for each year from 1997 to 2006. Prin projects are inter-organizational collaborations between researchers based in different Universities: each project is lead by a national coordinator, and involves a various number of local units, which must be based in different institutions. Therefore, the dataset consists of the names of all the units' coordinators (the national and the local ones), where the link represent their collaboration to a specific project. Given the fact that a researcher can only participate to one project every two years (projects are all funded for 24 months), ${ }^{3}$ each year's network is reduced to a number of disconnected stars (with ties between scientists and the specific projects they work on). Summing up the 10 bipartite matrices, the resulting network shows the stars' overlap, as researchers move from one project to the next one (and in some cases from one collaborative group to another) through the years. Data are supplemented with information about people's affiliations to Universities: while it is possible that scientists during their career move from one university to another, this is very unlikely in the Italian context, where people tend to be appointed and spend their entire career in the same University they obtained their PhD from (Beltrame, 2008). Although there are three distinct sets of nodes (people, projects, Universities), data do not form a tripartite network as relations are only defined by individual collaborations to research project, while institutional affiliation constitutes an attribute to individuals (multiple affiliation is not allowed and change in affiliation not recorded). However, it is still possible to apply matrix algebra and deduce the 'University by project' matrix, moving from the individual level of collaboration to the institutional one. ${ }^{4}$ Both the individual and the institutional matrices have been transposed, giving a 'people by people' valued network of number of projects in common, and the equivalent valued network for Universities. All networks are undirected.

\footnotetext{
3 This is true for funded projects, as every researcher, being national coordinator, local coordinator, or simple équipe member, can only work on one Prin project per time; but it is also true for Prin bids: when a group submits a proposal, all the members must be included only in one bid, therefore they cannot place their name in several projects in the hoping of having more chances to getting funded.

${ }^{4}$ This has been done by transforming the University affiliation attribute vector into a two mode binary 'University by people' matrix. This matrix is multiplied by the two mode binary 'people by project' matrix, obtaining a two mode valued 'University by project' matrix.
}

Given the redundancy of the Universities' network of collaborations to the individual ones, here it is not possible to fully apply Lazega et al. method of multilevel analysis. This is mainly due to the different context of research collaborations discussed in this paper. Lazega et al. (2008: 163) explore a wider range of inter-organizational collaborations, mapping exchanges between laboratories in terms of recruitment of post doc researchers, the development of programs of joint research, joint responses to tender offers, sharing of technical equipment, sharing of experimental material, mobility of administrative personnel, and invitations to conferences and seminars. In this paper I aim to explore only the specific cases of collaborations to Prin projects, where several research teams (the various units coordinated by the team leader whose name is reported in the data) get together for the specific purpose of working on a funded project. While collaborations are born by the individual agreement of scientists, it is still important to take into account the level of institutional affiliation, as one of the reason for selecting research partners might be the prestige of their departments. Therefore a multilevel approach is adopted here, but because it is not possible to collect data on multiplex exchange ties at an inter-organizational level, some other measures of the importance of the institutions are selected. Out of the possible ones, the size of the departments in terms of appointed researchers seems to be the most appropriate one, as it still retains a potential network value in terms of the number of colleagues each scientist can interact with on a daily basis. Working in a large department can be an advantage as there are more people scientists can seek advice from; or it could be a disadvantage as in a larger institutional setting people are less aware of each other (and therefore can count on less potential advice) than in smaller ones. Also, working in a big department might be counterproductive in terms of the number of projects funded every year, as Miur might limit funding to each institution (the scientific value of the projects assumed to being equal) in order to guarantee a balance between Universities.

Regardless the limit of the data, the study is innovative as:

- It applies a modified version of Lazega et al.'s method of analysis to a new dataset. Data refer to a different national context (Italy), for a different scientific community (physicists), for a larger set of individuals and projects ( 1122 scientists working on 455 projects and based in 66 Universities). It represents all the people and projects funded by Miur from 1997 to 2006, therefore it is not affected by missing data as the population is not sampled. Moreover, the analysis of the micro, the meso and the macro level of interaction is not limited to degree centrality (Lazega et al., 2008), but describes the characteristics of networks using several measures, such as the E-I index, brokerage scores, egonetwork density, and a core-periphery analysis.

- It observes a social network where relationships are collaboration to research projects, rather than classic co-authorships or co-citations. Without assuming that research projects are not selected according to the quality and the innovation of the proposal, I aim to test the impact of social and structural factors over the process of selection: this is reasonable given the fact that research proposals are evaluated not only in terms of innovation in a scientific field, but also taking into account the individuals' CVs and their reputation within the community of scientists. The analysis gives an insight into the mechanisms related to the process of funding, as it allows us to model the impact of individual variables (scientists' attributes), micro relational variables (scientists' collaborations), macro relational variables (Universities' affiliations), and meso level characteristics (the combination of the previous two levels) over the amount of money gained by researchers and institutions in 10 years time. 


\section{Overview of the system of Prin funding in Italy}

Hunting for funding is a highly competitive task in the life of a scientist. It is necessary because it is not possible to do research without finances that give access to human and material resources, because it increases the chances of getting a promotion, because it allows appointing junior staff, and because results are going to be published, and publications are the measure of scientific job performances. This is true for the Research Projects of National Interest (Prin) line of funding in Italy. The Prin is a form of cofunding between the Ministry of University and Research (Miur) and individual Universities. Every year, researchers obtain a budget from their Universities, which is available for funding $30 \%$ of a research project, the rest $70 \%$ being provided by Miur if the project is selected. In order to be funded, a research group must be organized around a national coordinator, and a variable number of local unities: every unit is based in a distinct University, and it is lead by a local coordinator.

Miur defines disciplines according to general areas (maths and informatics sciences, physical sciences, chemical sciences, biological sciences, social sciences, and the like) and every area is further divided in several sub-disciplines. For the area of physics, these are experimental physics, theoretical and mathematical physics, material physics, nuclear and sub-nuclear physics, astronomy and astrophysics, earth system physics, applied physics, and history and didactic of physics. Projects must be submitted for a specific area (physical sciences) but they can be interdisciplinary in terms of scientists involved. Thus, for example, it is possible to have a project where a theorist and a mathematician work together on some theoretical problems, or nuclear physicists work with engineers to develop new instruments, or particle physicists work with astrophysicists on an astro-particle project.

The information on funded projects is available from Miur website $^{5}$ : every funded project for every year (since 1997) is listed in a pdf file containing the name and affiliation of researchers together with their role (national coordinator, local unit coordinator), the amount of funded money for each unit, the title of the project and its description, including units' specific tasks. Each project must clearly state the expected innovations regarding the discipline state of art, the provisional number of publications, patents, conference presentations, PhD thesis, and other outcomes. Also, the rank of scientists (full professor, associate professor, and researcher ${ }^{6}$ ) and the sub-disciplinary affiliation are obtainable from the same source, together with the full list of all the physicists working in Italian Universities, including the ones who never got funded via Prin projects. In 2006 there were 3116 physicists working in 73 Universities; 1122 of them, who work in 66 Universities, have been funded during the 10 years under analysis. Of these 1122,8 people $(0.7 \%)$ have been national coordinators 4 times, 29 people (2.5\%) 3 times, 64 people (5.7\%) 2 times, 215 people $(19.1 \%)$ 1 time, and 806 people (72\%) have never been national coordinators. Being a national coordinator is an essential attribute, as s/he normally develops the original idea of the project, and establishes the initial contact with other local units to work on developing the idea. Because of the role of initiating collaborations, the national coordinator is also the one who usually receives more money if the project is funded.

The Miur website also provides some basic statistics on the number of projects funded over the number of proposed bids from 2001

\footnotetext{
5 www.miur.it.

6 The rank refers to the position occupied by every scientist in 2006. It was not possible to collect historical data that account for ranking improvement. This is a serious limit for the research, as it is likely that people in 1997 were in lower ranks than in 2006, and that some of the researchers were not yet in permanent positions.
}

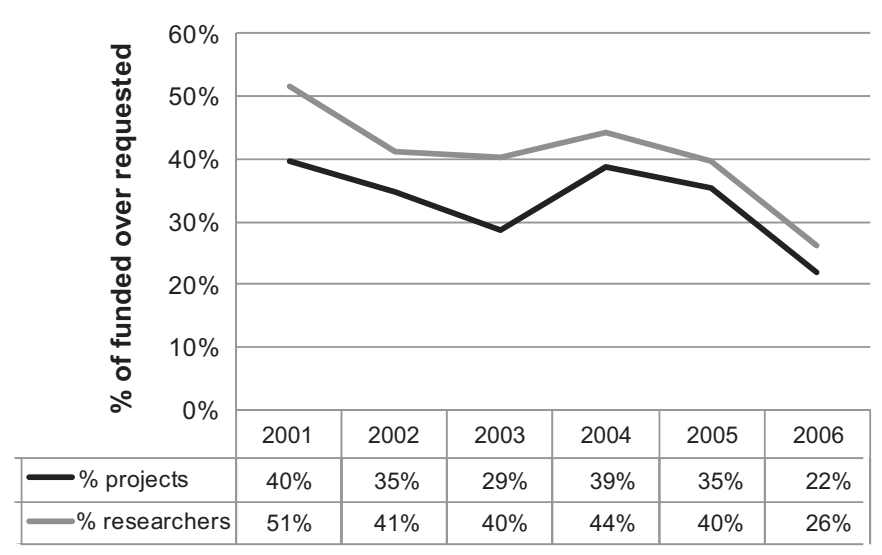

Fig. 1. \% of funded Prin projects and researchers from 2001 to 2006.

to 2006 (Fig. 1), which shows the decreasing percentage of successful projects over the years, with the exception of 2004. This means that from 2001 the competition over funding has increased, especially in 2006. All the research projects are funded for two years, which means that each research unit, if its project is selected, cannot place a bid or participate to any other project in the following year.

The ratio of the number of physicists in every sub-discipline funded via Prin projects over the total number of people funded indicates which sub-disciplines have been more represented in Prin projects in the last 10 years (Fig. 2). It is interesting to notice that while $25 \%$ of people involved in projects are affiliated to experimental physics, a good $18 \%$ comes from other disciplines, indicating physics' tendency to interdisciplinarity with external sectors. Applying the same ratio to the scientists' rank, over the total number of funded people $42 \%$ are full professors, $23 \%$ are associate professors, $7 \%$ are researchers, and $28 \%$ come from other disciplines (therefore rank is unknown).

This brief overview of the general characteristics of Prin system highlights some interesting features of the dataset. Within projects that do get funded via Prin, experimental physics, interdisciplinary projects, astronomy and material physics are privileged by Miur, possibly suggesting some long term political strategies of investment. Also rank seems to play an important role in gaining

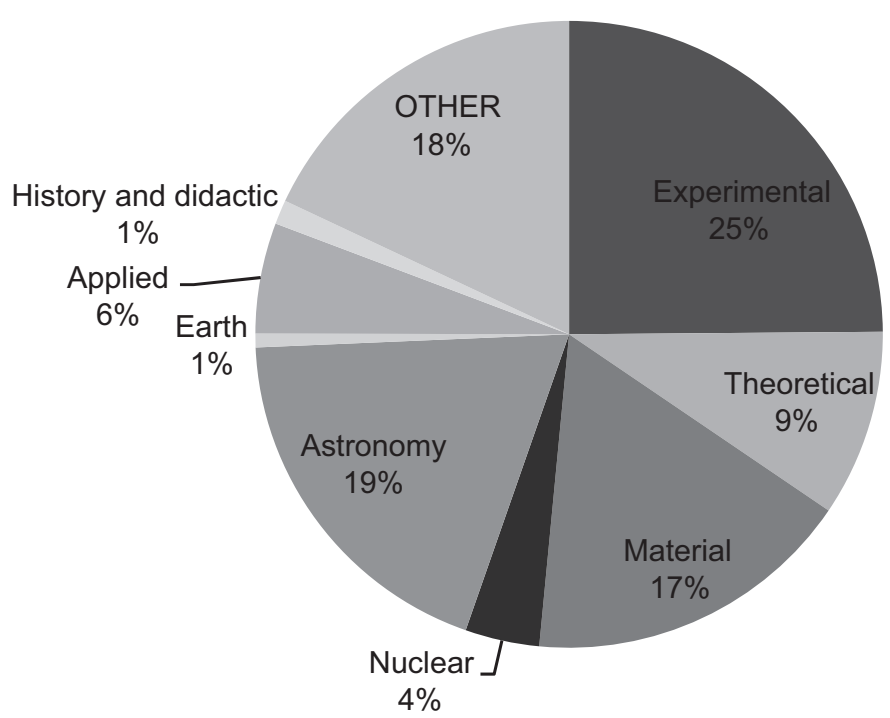

Fig. 2. \% of scientists in each sub-disciplines over the total $n$. of funded scientists. 
resources, with full professors dominating the process of getting funded. ${ }^{7}$

\section{The levels of interaction}

Sub-disciplines, rank and coordination roles can be considered as individual attributes of scientists involved in Prin projects. I now move to the analysis of the micro, the macro and the meso level of interactions. The micro level consists of the network of research collaborations between scientists. The macro level is obtained combining the micro network with scientists' affiliation to institutions: the outcome is a University by University matrix with number of projects in common, which does not add information to the network itself in terms of additional links, but it gives a different view of the collaboration process. The meso level is constructed by combining the individuals' number of collaborations (the micro level) with the size of their departments. This gives us a modified version of Lazega et al.'s system of classification (2008).

\subsection{The micro and the macro level}

The network of collaboration is obtained counting a tie between two researchers every time they are named in the same project. The result is a symmetric and valued square matrix, with actors in rows and columns and cells counting the number of collaborations. The size of personal networks range from 0 (no collaborations) to 39 (an actor collaborating with 39 alters), with a mean $=6.7$ and a median $=5$. Degree distribution range from 0 (a research project with only one unit, therefore only one scientist without any connections) to 73 (an actor collaborating 73 times with other people) with a mean $=9$ and a median $=5$. As it is valued, degree can indicate that a scientist participates to large research projects (with many other scientists) or to several of them (in the case of the one with 73 collaborations, he collaborates with 39 others, but with some of them more than one time). The network of individual collaborations has a density of 0.006 , and an average distance of 8.89 nodes, which means it is not highly dense, as cliques of projects summed up for 10 years do not dramatically overlap. Only 6 scientists (3 dyads) have the maximum of 5 projects in common, meaning they always collaborate with each other over the years. 17 groups of various sizes (from 2 to 12 ) have 4 projects in common, 33 groups (size range from 2 to 16) have 3 projects in common, and 80 groups of 2-48 nodes have 2 projects in common. 71 groups of size ranging from 1 to 774 have at least one project in common (Fig. 3). At this minimum level of collaboration, the main component accounts for $69 \%$ of scientists, the second largest one for only $2 \%$ ( 24 nodes).

This structure suggests that there are at least two strategies of getting connected to achieve funding. On one hand, some research groups tend to collaborate over the years, strengthening their mutual relationship: they either develop long term research plans, asking for funding for follow-up projects, or they simply collectively decide where to invest their research efforts as a group over the years. On the other hand, some researchers tend to change the composition of research groups over time: overall, they end up occupying a brokerage position ${ }^{8}$ between different sets of

\footnotetext{
${ }^{7}$ Given the fact rank refers only to the scientists' positions in 2006, therefore at the end of the period data refer to, it could be that being funded is the factor that made scientists progressing in ranks, rather than being funded because of their high rank. However, it is still important to notice the correlation between high ranks and successful funding.

${ }^{8}$ A brokerage position is defined as the number of times ego lies on the shortest path between two alters (i.e., the number of pairs of alters that are not directly connected). In the regression model presented in section 5 of the paper I use the normalized version of this measure, where the number of brokerage opportunities, which is a function of ego network size, is taken into account.
}

people, increasing the number of personal contacts which would be otherwise disconnected. The two strategies are not mutually exclusive: someone might collaborate with one group one year, add new people to the original group two years later (therefore his/her egonetwork will be a larger clique with ties value $=1$ for relationships from the first group with the second group, and ties value $=2$ for relationships within the first group), and eventually move to collaborate with a third group after other two years, therefore finding him/herself in the position of being the only link between groups 1 and 2 and group 3. These strategies resemble the ones theorised by Burt (2005), who distinguishes between brokerage and closure in organizational settings, where brokerage seems to favour the development of new ideas, while closure the delivery of settled projects. In Burt's theory, both strategies are valuable in terms of social capital, as when combined they maximise the advantage for actors of having dense egonetworks which facilitate the development of trust and behavioural control, and gaining different and exclusive perspectives from otherwise disconnected people. In this case I cannot assume that closure implies shared behavioural control and higher level of trust and commitment. In the same way, a brokerage position does not automatically entail a knowledge transfer between otherwise disconnected groups: the reasons why someone decides to move across different groups can be various, and cannot be surmised from this kind of data. But in terms of potential social capital, he/she can count on personal relationships with unconnected sets of colleagues.

Within the population under study, 614 researchers have a brokerage score equal to 0 ( $60 \%$ out of the 1122 physicists), while the remaining $40 \%$ have a brokerage score ranging from 0.1 to $1: 157$ $(14 \%)$ have a value $>0$ and $<0.33,246(22 \%)$ have a value $\geq 0.33$ and $<0.66$, and $49(4 \%)$ have a value $\geq 0.66$ to 1 . In terms of closure, the density of egonetworks (calculated taking into account the values of the ties) range from 0 to 4 , with 300 people (27\%) with values $\geq 0<1 ; 345$ (31\%) people with values $=1 ; 305$ (27\%) with values $>1<2$; and $116(10 \%)$ with values $\geq 2$ and $\leq 4$. For 56 people density and brokerage values cannot be calculated as they are isolates. ${ }^{9}$

I model the success of these strategies in the final section of the paper, in order to test which of the two proves to be more successful for obtaining money. While here I am assuming a direction of causation from the structure to the level of funding, it could also be the case that people become popular as they received funding in the past, and therefore attract new collaborators. Disentangling the direction of causation can only be empirically tested with temporal analysis, where it would be possible to see if it is the position in the structure of collaboration that favour the amount of received funding, or if it is the amount of funding that stimulate further collaborations. ${ }^{10}$ However, this latter direction of causation would imply a higher impact of closure than brokerage over the total amount of money received in the ten years under analysis: this hypothesis is tested in the final section of the paper, and results thus suggest a possible direction of causation.

\footnotetext{
${ }^{9}$ I also tried to combine egonetwork density with brokerage scores by multiplying the two together, in order to create a measure of "mixed" strategies (for people having an average level of density and an average level of brokerage). The new combined measure behaves exactly like brokerage scores in the final regression model, suggesting that it is still a brokerage role which makes most of the differences in terms of getting funded. This is mainly because $60 \%$ of the population have brokerage scores $=0$, therefore when multiplied by density they delete the value of closure, reinforcing the one of brokerage.

10 A longitudinal analysis of the data is not performed for several reasons. The first one is that for each year networks include a completely different set of actors and projects, therefore dynamic network analysis cannot be performed for the lack of congruence between nodes in each time observation. The second one is the fact that the original network is bipartite, therefore it requires the development of new methodologies, for example some extension of Siena bipartite models.
} 
At least 1 collaboration
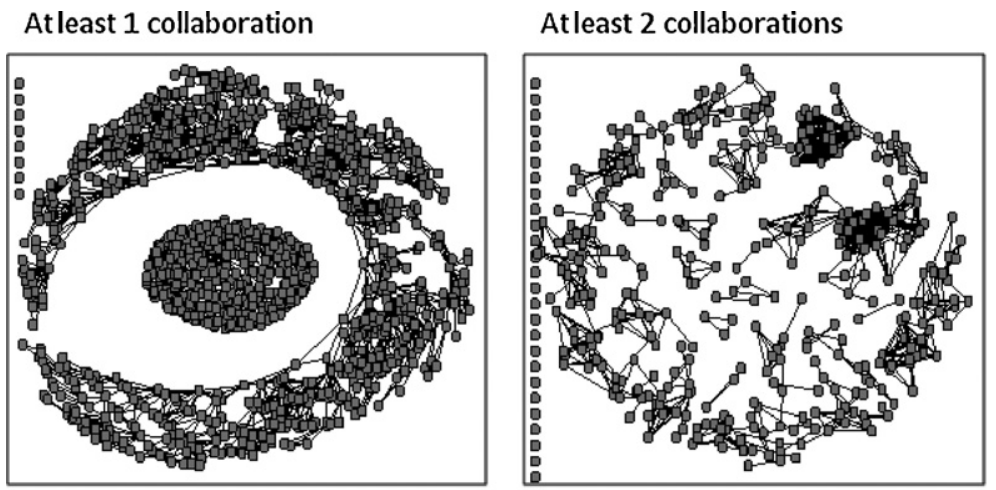

At least 3 collaborations

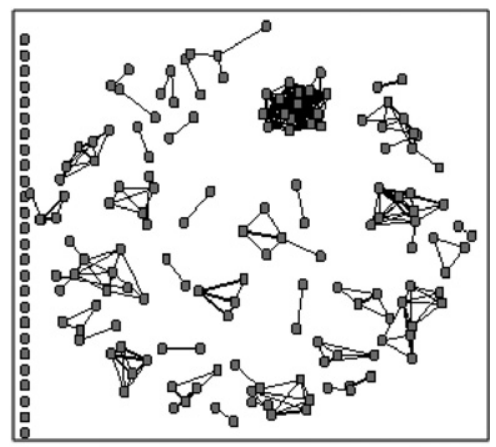

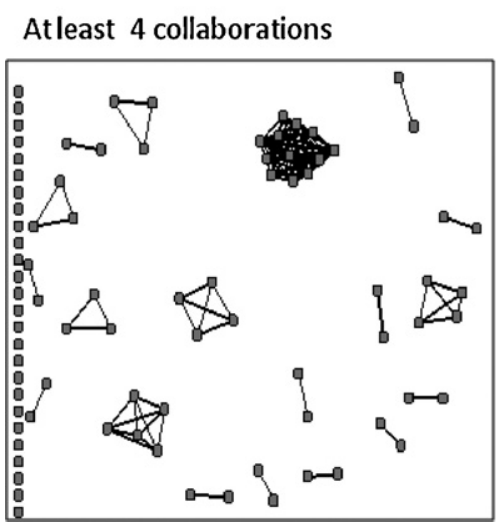

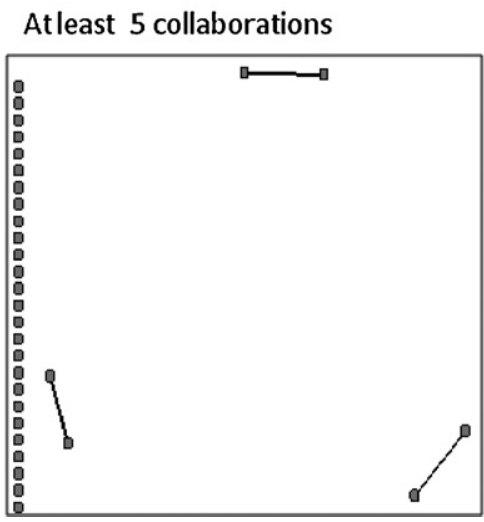

Fig. 3. Number of collaborations to research projects.

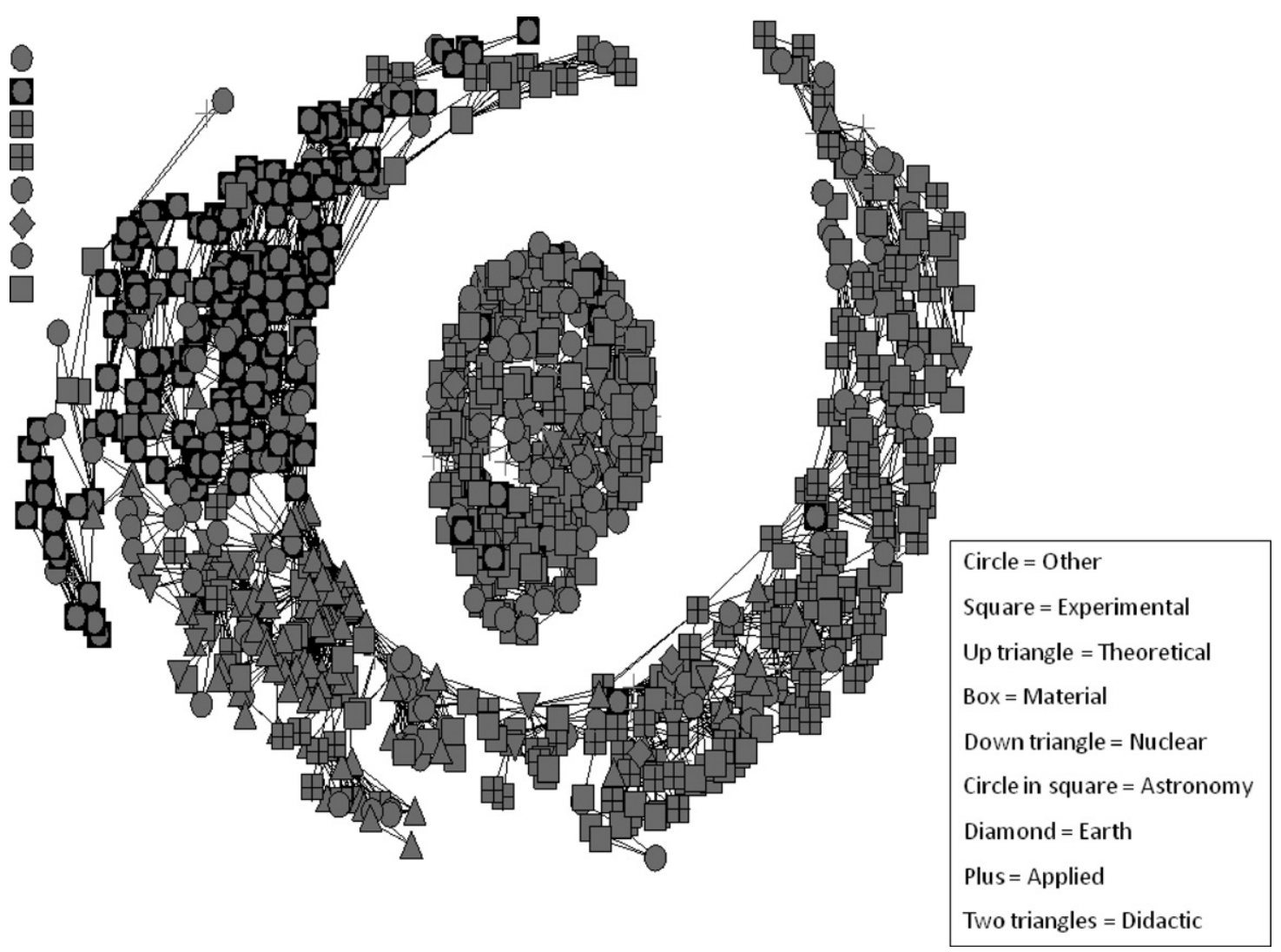

Fig. 4. The network of individual collaborations. Nodes shaped according to sub-disciplines. 
Table 1

E-I index for sub-disciplines.

\begin{tabular}{lrrrl}
\hline & Internal & External & Total & E-I \\
\hline Other & 242 & 1105 & 1347 & 0.641 \\
Experimental & 484 & 1447 & 1931 & 0.499 \\
Theoretical & 46 & 611 & 657 & 0.86 \\
Material & 268 & 1129 & 1397 & 0.616 \\
Nuclear & 8 & 241 & 249 & 0.936 \\
Astronomy & 266 & 1114 & 1380 & 0.614 \\
Earth & 0 & 25 & 25 & 1 \\
Applied & 28 & 383 & 411 & 0.864 \\
History and didactic & 0 & 89 & 89 & 1 \\
\hline
\end{tabular}

Table 2

E-I index for rank.

\begin{tabular}{lccrc}
\hline & Internal & External & Total & \multicolumn{1}{c}{ E-I } \\
\hline Other & 456 & 1032 & 1488 & 0.387 \\
Researcher & 6 & 179 & 185 & 0.935 \\
Associate & 138 & 741 & 879 & 0.686 \\
Professor & 1338 & 1218 & 2556 & -0.047 \\
\hline
\end{tabular}

Within the network sub-disciplines are clustered differently (Fig. 4): while nuclear physics is scattered around the whole network, experimental physics, material physics and astronomy/astrophysics are slightly more clustered. This is evident from the E-I index values (Krackhardt and Stern, 1988, cfr. Table 1). EI index are positive for all the sub-disciplines (with theoretical, nuclear, earth, applied and history scoring higher than 0.8 ), but slightly lower for experimental physics (0.499), astronomy (0.614), material physics (0.616), and other disciplines (0.641).

While sub-disciplines show very positive E-I index values, indicating a high level of interdisciplinarity within different areas of physics and other scientific areas, the same values calculated for ranks tell a different story (Table 2). Here full professors show E-I index values very close to $0(-0.04)$ indicating a balance of interactions with peers at the same rank level and people in lower positions. On the other hand, people in lower positions score very high on E-I index values ( 0.686 for associate professors, 0.935 for researchers) indicating their need to interact with higher ranks in order to get funded.

As briefly explained above, the network of collaborations between Universities is obtained combining the micro level of interactions between scientists with their affiliations to institutions. While network data are completely derivable from these two matrices, it is still interesting to observe the structure of collaborations at the macro level of institutions, as it provides a different perspective. The University by University network, with number of projects in common, has a density of 0.48 , and an average distance of 1.53 . Valued degree ranges from 3 to 558 , with a mean $=147$. It presents a quite distinctive core-periphery structure, with 19 Universities in the core with an average value of $11.57,{ }^{11} 47$ in the periphery with an average value of 0.68 , and average value of connection between core and periphery of 2.38 (Fig. 5). Out of the core, the analysis of factions reveals a periphery with two subgroups: one is mainly composed by astronomy observatories, which seem to play a distinct role from the rest of institutions in the network. The other includes some minor Universities scattered around the core.

There are several ways to account for institutional success. One of them can be the amount of received funding, with 17 Universities getting over 2 millions euro in the 10 years under study (Fig. 6).

\footnotetext{
11 Given the fact the network is valued, the density within and between core and periphery does not range between 0 and 1 , but it shows the average value of connections.
}

These are mainly the core institutions, as correlation between the total amount of funding and the coreness values is very high (0.854). Other criteria are the number of physicists working in every institution, where again core institutions seem to be the ones with the larger number of appointed physicists (Fig. 5). The number of physicists working in Italian universities (the total $=3116$ ) range from 1 (Campus Bio Medico Roma) to 180 (Rome) with a mean $=42$. On average $37 \%$ of all the physicists were involved in Prin projects in the last 10 years, with institutions like Rome, Florence, Padua, Pisa and Naples where over 40 researchers have been successfully funded. ${ }^{12}$

The analysis of the micro and the macro level of interactions suggest some important properties of the overall network of collaborations. First of all, interdisciplinarity seems to be a privileged strategy to gain funding, both in terms of collaborations with other scientific area (math, engineering, philosophy, and the like), and within subdisciplines (theoretical, experimental, nuclear, and the like). Second, rank is still playing an important part in the formation of research groups, with lower ranks seeking collaborations with full professors. Third, brokering between different research groups for different projects, or clustering groups together over time, seems to represent two distinct and combinable strategies for obtaining funding. Finally, working in a university with a higher number of physicists seems to give an advantage in terms of collaborations, as larger departments tend to be in the core of the institutional network.

\subsection{The meso level: fishes and ponds in Italian physics}

While in the previous section I analysed the micro and the macro level separately, here I move to combining the two together in order to observe the meso level of interaction. This is done by adapting Lazega et al. (2008) method of classification. The authors create four categories, two for people and two for institutions, using degree values as threshold (actors and institutions with degree values above the median are big fishes and big ponds, while the ones with degree values below the median are little fishes and little ponds). Combining them, they came out with the subsequent four categories: big fish in big pond, little fish in big pond, big fish in little pond and little fish in little pond.

Similarly, here I consider big fishes scientists with a valued degree above the median (as the distribution is skewed): within the 1122 scientists, 535 are big fishes, 587 little fishes. As the network of University is redundant to the network of individuals, it does not make sense to use again degree values to distinguish between ponds. Therefore the distinction is calculated on the number of physicists working in every institution, regardless being funded or not. The assumption is that an organization with a higher number of physicists offers a potential larger pool of contacts. ${ }^{13}$ I consider big ponds Universities with a number of appointed physicists above the mean $=42$ (the distribution is not skewed). Over the 73 Universities with at least 1 physicist 66 have obtained Prin funding from 1997 to 2006: 32 are big ponds and 34 are little ponds.

Combining together information about fishes and ponds, I derive the same four categories of Lazega et al. (2008), obtaining 424 big fishes in big ponds (BFBP), 460 little fishes in big ponds (LFBP), 111

\footnotetext{
12 Correlation between institutions' coreness and the total number of people working in a department is 0.851 ; with total number of funded people per department is 0.896 .

13 There could have been other methods to distinguish between big ponds and little ponds. A valuable one is to consider big ponds Universities that get ranked in a worldwide University ranking system: the measure offers interesting information over institutions, but it does not represent a potential network measure, while the number of colleagues working in a University offers an estimate of potential contacts a scientist can count on.
} 


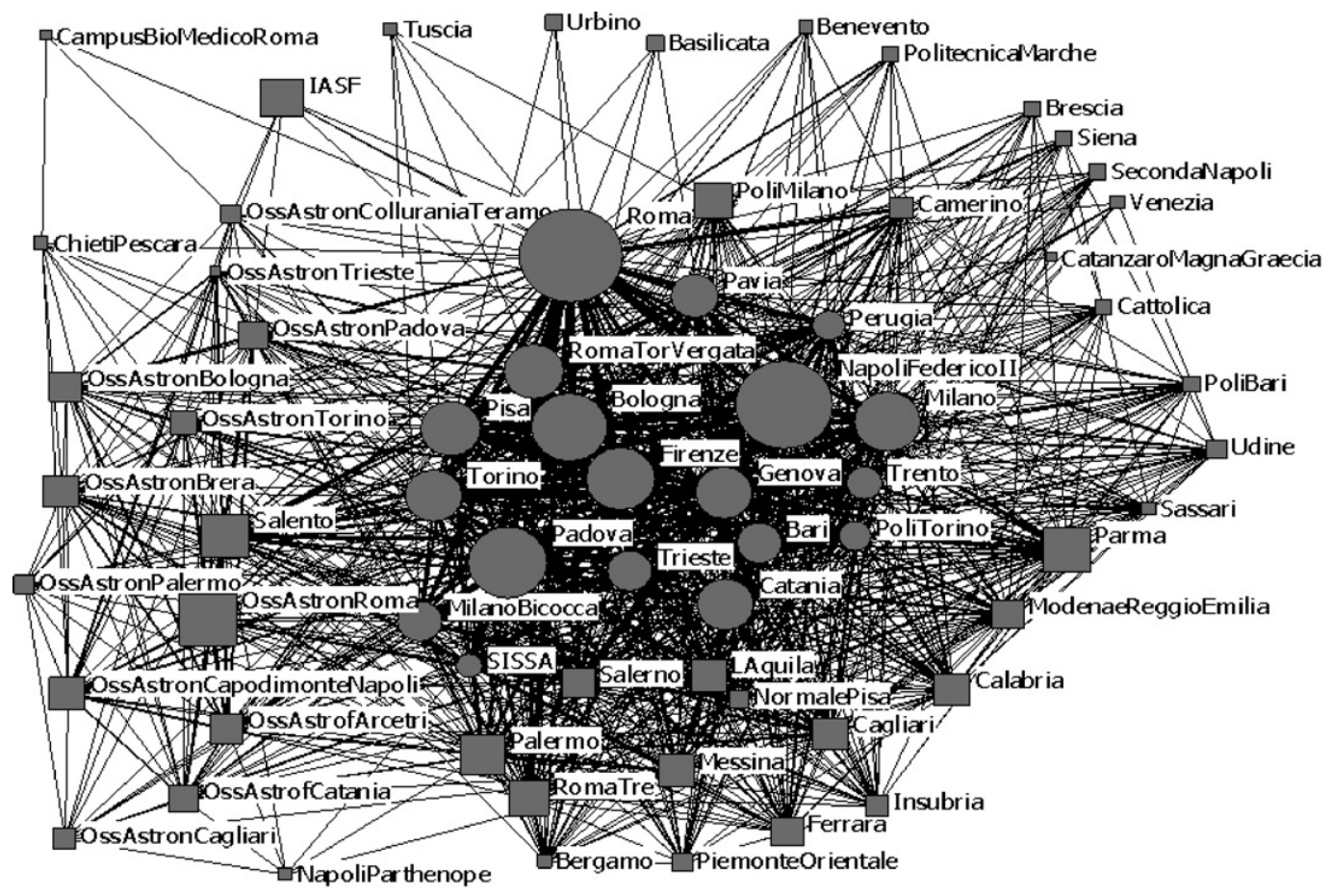

Line size: number of projects in common Node size: number of scientists working in the University Circles: core nodes

Squares: periphery nodes

Fig. 5. University by University network with number of projects in common.

big fishes in little ponds (BFLP) and 127 little fishes in little ponds (LFLP). The high number of people working in big ponds probably resembles the fact that physics tends to concentrate in large departments, which are also the ones that historically developed the discipline after the Second World War: as the tendency was to move toward the model of big science, human and economic resources have been concentrated in major departments like Rome, Padua, Turin, and Milan, where investments in physics were already a priority.

If we look at the distribution of fish and pond categories in every sub-disciplines (Fig. 7), we find that experimental physics is dominated by LFBP (48\%) followed by BFBP (34\%), similarly to material physics, where LFBP account for $42 \%$ of scientists, followed by BFBP (33\%). BFBP dominate theoretical physicists (60\%) nuclear physics ( $56 \%$, followed by $26 \%$ of LFBP), astronomy ( $40 \%$, followed by $32 \%$ of LFBP) and history and didactic of physics (71\%), while LFBP count for $50 \%$ of earth physics and $48 \%$ of applied physics. Other disciplines see $54 \%$ of their researchers in LFBP, suggesting that they might be big fishes in other sectors. LFLP and BFLP, given their lower numbers, represent minorities in all the sub disciplines.

Regarding the rank (Fig. 8), LFBP account for $53 \%$ of researchers, followed by LFLP (24\%). Associate professors are mainly constituted by LFBP (47\%) and BFBP (34\%), while full professors are mainly made of BFBP (49\%) followed by LFBP (34\%). Researchers from other

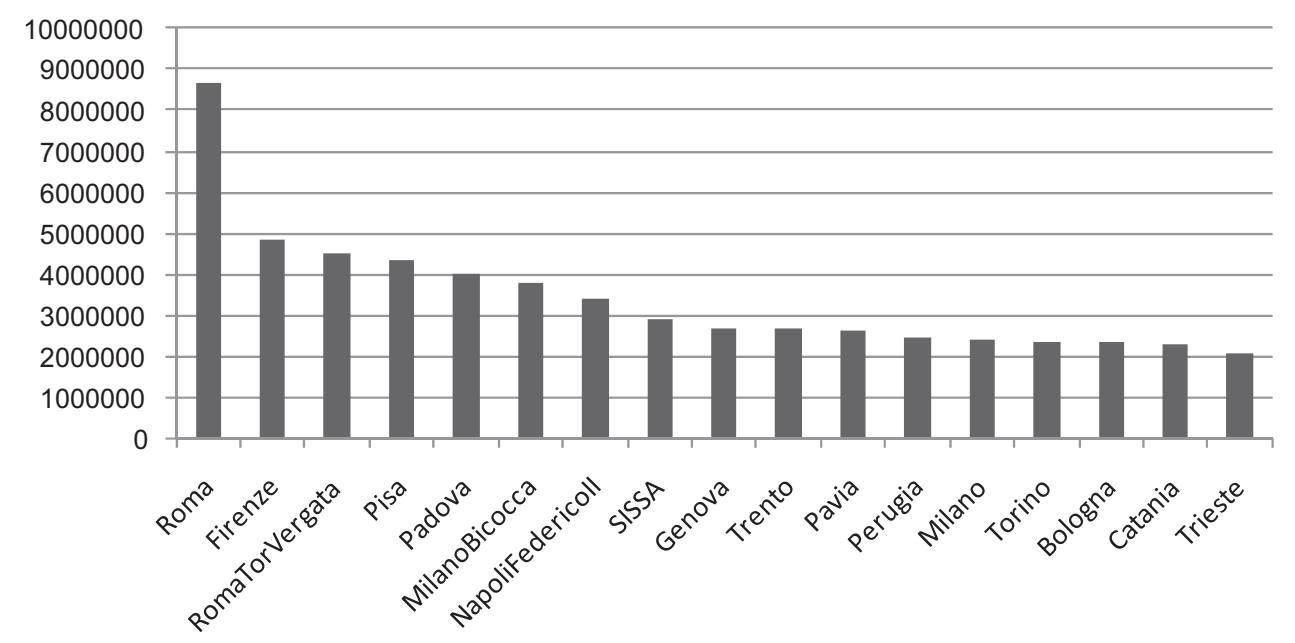

Fig. 6. Total amount of money received by top funded Universities (over 2,000,000€). 


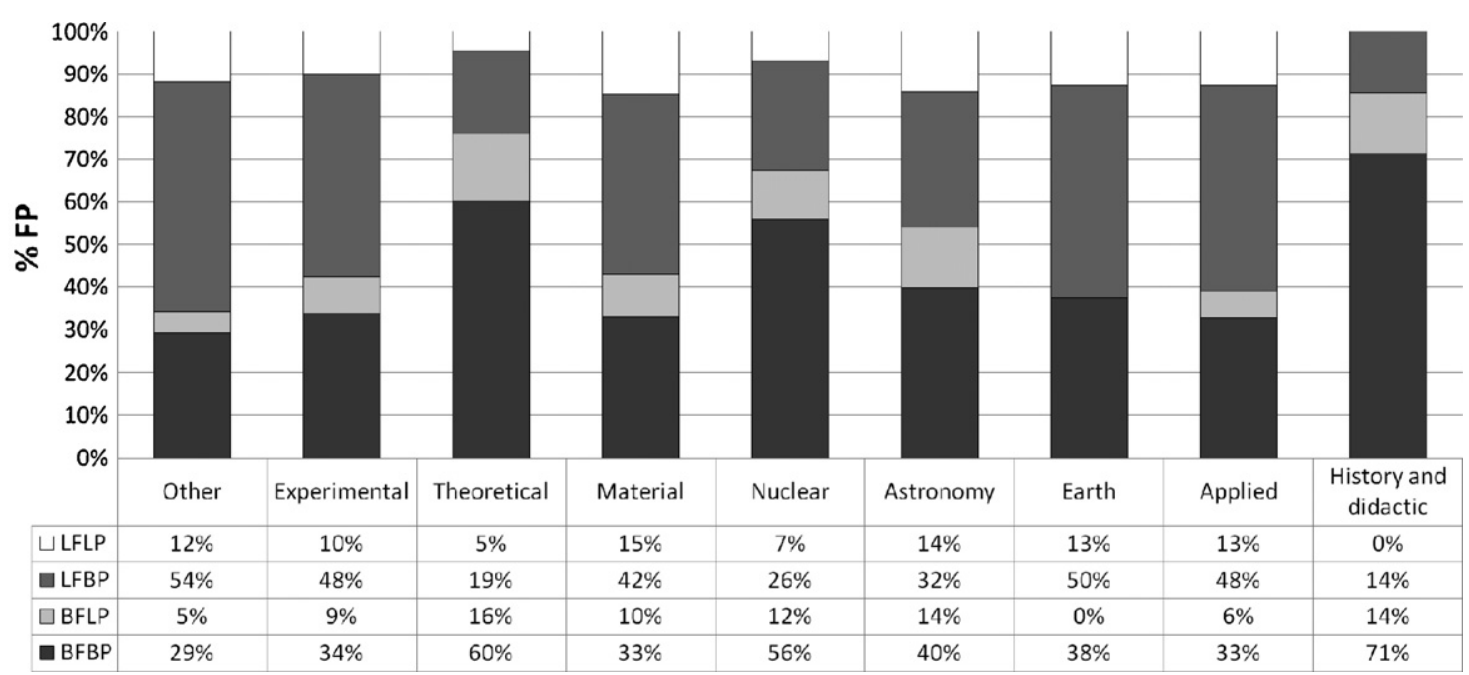

Fig. 7. \% of fish and pond categories in each sub-disciplines.

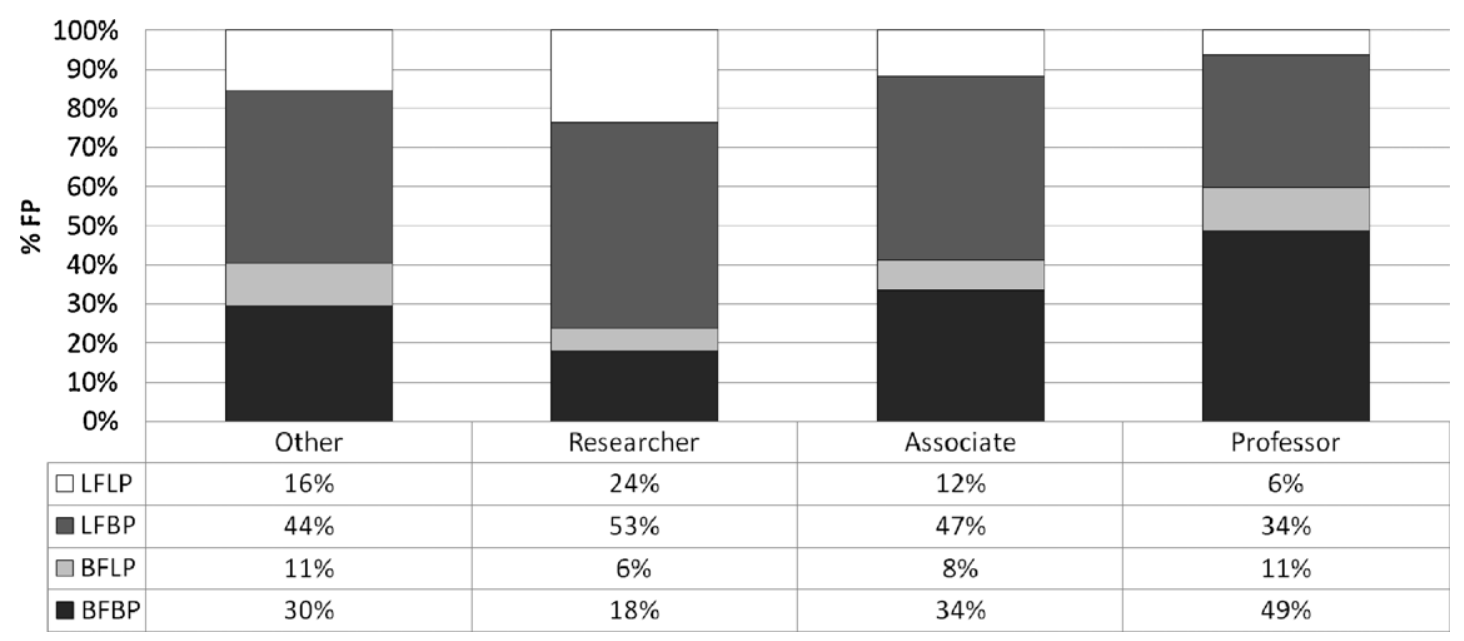

Fig. 8. \% of fish and pond categories in each rank.

disciplines are mostly BFBP (30\%) and LFBP (44\%), strengthening the possibility that they are big fishes in their own sectors.

Overall, the meso level indicates that better connected scientists tend to work in large departments, and that there is a correlation between rank and the position of scientists in the meso level of connections, with big fishes in big ponds decreasing in numbers in subsequent lower ranks.

\section{Modelling funding achievements}

While in most of sociology of science studies academic success is measured in terms of publications and impact factor, in this study success is represented by the total amount of funding a researcher has achieved in the last 10 years. So far, I have analysed the networks characteristics in terms of getting connected with other researchers, without taking into account the amount of money received for every projects scientists get involved into. While it is likely that participating to a higher number of projects means obtaining more funding, this could not be always the case, as a scientist can participate to fewer but better funded projects. In the last part of the article, I model the amount of money obtained by every researcher in the last 10 years against the variables that emerged as important at the individual, micro, macro and meso level of analysis. I model each level hierarchically, in order to measure its influence separately from the other levels. ${ }^{14}$

At the individual level, I expect national coordinators and full professors to be more successful in obtaining money for research, as well as the affiliation to specific sub-disciplines, like experimental physics, astronomy and astrophysics, and material physics, or to other disciplines. Here the direction of causality must be taken with caution, as it could be that previous success in obtaining funding increases individuals' credibility and facilitate them in convincing other people to join their projects in subsequent years; similarly, the capability of obtaining funding might contribute to careers'

\footnotetext{
14 Like in most network data, the assumption of the cases' independence is unrealistic. As people are related to each other, and when they collaborate they tend to equally share the total amount of funding between the local units (with the exception of the national coordinator), we should expect several functional dependencies. The simplest way of correcting for potential lack of independence between cases due to a network with adjacency matrix $W^{*}$ is to use the Network Disturbances model (Leenders, 2002). I fitted the model with the same covariates in Table 5, and the results do not vary dramatically from the standard regression. As expected there is a very large network correlation - the estimate of the feedback parameter is 0.5 and the standard error is 0.05 . The diagnostics show that there are some very large residuals but there are no alarming departures from model assumptions. I would like to thank Johan Koskinen for suggesting the solution to the problem of the lack of independence.
} 
advances. The inverse direction of causality is less likely for subdisciplines, as it is difficult that a scientist changes his/her discipline affiliation to invest in more successful fields.

H1. On average, national coordinators are more likely to obtain a larger amount of money for research than researchers who never lead a research group.

H2. On average, full professors are more likely to obtain a larger amount of money for research than other ranks.

H3. On average, researchers working on experimental physics, astronomy, and material physics, and in other disciplines, are more likely to obtain a larger amount of money than researchers working in other sub-disciplines.

At the micro level of collaborations to research project I expect projects with a higher level of interdisciplinarity to be more successful. This is represented by the E-I index values calculated for sub-disciplines. Again, direction of causality cannot be robustly tested, as it could be the case that people who received funding for interdisciplinary collaborations will continue in the same direction.

I also want to measure the successful rate of researchers occupying a brokerage position or being involved in dense egonetworks: following Burt (2005), I expect both brokerage scores and egonetwork density (which, for valued networks, is equal to the average value of ties) to impact on the total amount of funding. If the direction of causality is reversed, I would expect closure to be the most successful strategy.

H4. On average, researchers with higher E-I index values for subdisciplines are more likely to obtain a larger amount of money for research than the ones with lower values.

H5. On average, researchers with higher ego brokerage scores and/or higher egonetwork density are more likely to obtain a larger amount of money for research than researcher with low values in one or both measures.

At the macro level, given the fact that core institutions seem to be the ones getting more funding, I expect scientists working in them to be more successful than the ones working in peripheral Universities. Here the direction of causality is more robust, as given the low level of mobility of Italian researchers it is very unlikely that a scientist decides to move to a core institution attracted by the higher level of funding received by core departments.

H6. On average, researchers working in core institutions are more likely to obtain a larger amount of money for research than researcher working in peripheral ones.

At the meso level, which combines the size of the egonetworks (degree) with the size of departments scientists work for (number of appointed physicists), I expect big fishes in big ponds to be more successful than other categories, given the fact that in order to be a big fish scientists must have collaborated to more research projects than the median (therefore with a higher possibility of obtaining more money), and that big ponds might be considered more prestigious institutions, therefore attracting a higher level of funding. The direction of causality could be partially affected by the previous amount of funding, as successful projects can be criteria of evaluation for future bids; however, being appointed in a big pond due to the previous amount of received funding is again very unlikely given the low mobility of Italian scientists.

H7. On average, big fishes in big ponds (BFBP) are more likely to obtain a larger amount of money for research than little fishes in big ponds (LFBP), big fishes in little ponds (BFLP) and little fishes in little ponds (LFLP).

In all the models the log of money values (as the sum of every funding granted to every researcher over the 10 years) is the
Table 3

Descriptive statistics of variables.

\begin{tabular}{|c|c|c|c|c|}
\hline Variable & $\begin{array}{l}\text { Abs. } \\
\text { values }\end{array}$ & $\%$ & $\begin{array}{l}\text { Average } \\
\text { value }\end{array}$ & Range \\
\hline National coordinator & (at least 1 time) 316 & $28 \%$ & & $0 / 4$ \\
\hline Professor & 470 & $42 \%$ & & \\
\hline Associate & 259 & $23 \%$ & & \\
\hline Researchers & 72 & $7 \%$ & & \\
\hline Other rank & 321 & $28 \%$ & & \\
\hline Experimental & 279 & $25 \%$ & & \\
\hline Theoretical & 108 & $10 \%$ & & \\
\hline Material & 191 & $17 \%$ & & \\
\hline Nuclear & 43 & $4 \%$ & & \\
\hline Astronomy & 213 & $19 \%$ & & \\
\hline Earth & 8 & $1 \%$ & & \\
\hline Applied & 64 & $6 \%$ & & \\
\hline History and didactic & 14 & $1 \%$ & & \\
\hline Other discipline & 202 & $18 \%$ & & \\
\hline E-I for disciplines & & & 0.64 & $-1 / 1$ \\
\hline Egonet valued density & & & 1.14 & $0 / 4$ \\
\hline $\begin{array}{l}\text { Normalized brokerage } \\
\text { scores }\end{array}$ & & & 0.16 & $0 / 1$ \\
\hline Core & 791 & $70 \%$ & & \\
\hline BFBP & 424 & $38 \%$ & & \\
\hline BFLP & 111 & $10 \%$ & & \\
\hline LFBP & 460 & $41 \%$ & & \\
\hline LFLP & 127 & $11 \%$ & & \\
\hline
\end{tabular}

dependent variable. ${ }^{15}$ The analysis is done on 1121 people rather than 1122, as there is an outliner case of someone who participated to a project without getting any money, which is likely to be a case of imputation error.

In the first model I introduce the variable of being a national coordinator (no roles as national coordinator as constant). In the second model I introduce variables related to rank (full professor as constant, associate professor, researcher, rank unknown). In the third model I introduce variables related to sub-disciplines (experimental physics as constant, theoretical, nuclear, material, astronomy, earth, applied, didactic, other). In the fourth model E-I values for sub-disciplines (ranging from -1 to +1 ), brokerage scores (ranging from 0 to 1 ) and egonetwork valued density (ranging from 0 to 4 ) are introduced ( -1 scores for E-I and 0 values for brokerage and closure being constant). In the fifth model I take into account core values, being in the periphery as constant. In the sixth and final model, the meso categories are introduced (BFBP as constant, BFLP, LFBP, LFLP). Summary of variables' values is presented in Table $3 .^{16}$

Outputs of the models are displayed in Table 4, which reports the values for $R, R^{2}$ and standard errors, and in Table 5 reporting coefficients for every variable.

The first model, which takes into account how many times scientists have been in the role of national coordinators, explains alone $13.8 \%$ of the variance: being a national coordinator increase the total amount of money from an average of $€ 50.868$ to an average of $€ 77.324$, and values are significant. Therefore hypothesis 1 is confirmed: this can be considered as a control variable, as the national coordinator is in most of the cases the one who sets up the project and obtains the largest part of the funding.

The second model, which includes the scientists ranks, does not explain much of the variation in the amount of funding $\left(R^{2}\right.$ rises

\footnotetext{
15 I use the log of the money as values are not normally distributed.

16 All the variables have low levels of correlations among them. Highest levels of correlations are associate/other rank $(-0.35)$, National coordinator/brokerage roles (0.35), other rank/other disciplines ( 0.74 , which is expectable as other rank indicates people working in other disciplines, but it is not completely correlated as there might also be physicists working in other disciplinary areas), sfbp/brokerage $(-0.36$, this is sensible to the fact that little fishes have less ties, therefore less probability to be a broker, bflp/core $(-0.36)$ and sflp/core $(-0.40$ these last two correlations are sensible to the fact that core institutions are also the bigger ones).
} 
Table 4

Model summary.

\begin{tabular}{lllll}
\hline Model & $R$ & $R$ square & Adjusted $R$ square & $\begin{array}{l}\text { Std. error of the } \\
\text { estimate }\end{array}$ \\
\hline 1 & $.373^{\mathrm{a}}$ & .139 & .138 & .8050 \\
2 & $.424^{\mathrm{b}}$ & .179 & .176 & .7870 \\
3 & $.445^{\mathrm{c}}$ & .198 & .189 & .7808 \\
4 & $.589^{\mathrm{d}}$ & .347 & .338 & .7057 \\
5 & $.590^{\mathrm{e}}$ & .348 & .338 & .7054 \\
6 & $.601^{\mathrm{f}}$ & .361 & .350 & .6990 \\
\hline
\end{tabular}

a Predictors: (constant), national coordinator.

b Predictors: (constant: full professor), other rank, researcher, associate.

c Predictors: (constant: full professor, experimental), other rank, researcher, associate, history and didactic, earth, nuclear, applied, theoretical, astronomy, material, other discipline.

d Predictors: (constant: full professor, experimental, E-I disciplines $=-1$, normalized broker $=0$ ), other rank, researcher, associate, history and didactic, earth, nuclear, applied, theoretical, astronomy, material, other discipline, E-I disciplines, normalized broker, egonet density.

e Predictors: (constant: full professor, experimental, E-I disciplines $=-1$, normalized broker $=0$, Periphery), other rank, researcher, associate, history and didactic, earth, nuclear, applied, theoretical, astronomy, material, other discipline, E-I disciplines, normalized broker, egonet density, core.

f Predictors: (constant: full professor, experimental, E-I disciplines $=-1$, normalized broker $=0$, Periphery, BFBP), other rank, researcher, associate, history and didactic, earth, nuclear, applied, theoretical, astronomy, material, other discipline, E-I disciplines, normalized broker, egonet density, core, BFLP, LFBP, LFLP.

up only to $17.6 \%$ ) but it is significant: full professors have gained on average $€ 63.767$ over the 10 years under analysis, compared to $€ 47.619$ earned by associate professors, $€ 39.104$ by researchers, and $€ 44.222$ by scientists whose rank is unknown (as they are not physicists). Therefore hypothesis 2 is confirmed. In the third model, sub-disciplines are included, but most of them do not play a significant role in access funding (working in experimental physics is significant, but it does not increase the average amount of money obtained by full professors; working in applied physics, history and didactic, and other disciplines ${ }^{17}$ significantly decreases the amount of funding from the average $€ 63.386$ of experimental physics to, respectively, $€ 48.194$, $€ 39.537$, and $€ 46.676)$. Also, they do not increase the overall explanation $\left(R^{2}\right.$ only rises up to $18.9 \%$ ). hypothesis 3 is thus not confirmed, especially for projects involving other disciplines which receive on average less funding that physics projects.

The fourth model adds the network variables of the micro level of interactions, and it explains much more of the variance $\left(R^{2}\right.$ is now up to $33.8 \%$ ). On average, professors with -1 E-I values, 0 brokerage scores and 0 density obtain $€ 42.320$. But while the EI index calculated for disciplines is not significant, a brokerage role is highly significant and counts for a substantial increase in the amount of funding. For example, having a brokerage score of 0.2 increases the average amount of obtained funding to $€ 59.481$, having a brokerage score of 0.5 increases it to $€ 99.111$, and having a maximum brokerage score of 1 increases it to $€ 232.118$. At the same time, egonetwork valued density is also positively significant: having a density of 0.5 increases the average amount of funding to $45.936 €$, a density of 1.5 increases it to $54.123 €$, a density of 2.5 increases it to $63.768 €$, and a maximum density of 4 increases it to $81.553 €$. Thus hypothesis 4 is not confirmed, while hypothesis 5 is: brokers gain much more advantage than their colleagues in terms of funding, but closure is a valuable strategy too, even if not successful as brokerage. Interestingly, brokerage roles diminish the gap between full professors and other physicists' ranks, indicating that occupying a strategic position in terms of connecting different

\footnotetext{
17 The inclusion of disciplines in the model turns the unknown rank non significant: this is probably due to the fact that the variables "other rank" and "other disciplines" are highly correlated (74\%), therefore one diminishes the effect of the other.
}

groups can reduce the competition with full professors. Also, brokerage scores make astronomy negatively significant, suggesting that playing a brokerage role is a strategy that does not work well for astronomers. Astronomy observatories, in the macro analysis of Universities' positions in the network of institutional collaborations, came out as part of the peripheral faction with an internal density higher then the rest of the periphery: this suggests that closure might be a strategy that suits astronomy better, but results are not significant. ${ }^{18}$

The fifth model takes into account working in a core institution. This is not significant, and it does not explain any more variance $\left(R^{2}\right.$ is still 33.8\%). Therefore hypothesis 6 is not confirmed. The sixth and final model takes into account the meso level network variables, which explain a slightly higher variance ( $R^{2}$ is $\left.35 \%\right)$. Big fishes in big ponds do obtain on average more funding than little fishes in big ponds ( $€ 47.811$ compared to $€ 37.572$ ), and than little fishes in little ponds ( $€ 40.498$ ) and the values are significant, but values for big fishes in little ponds are not significant. Therefore hypothesis 7 is only partially confirmed. Here it is interesting to notice that little fishes are generally penalised against the big fishes, but little fishes in big ponds are more penalised than little fishes in little ponds, as the former gain on average less funding that the latter. Moreover, the meso level variables diminish the positive effect of brokerage and closure, indicating the importance of keeping into account the size of the institutions.

\section{Discussion}

Data analysis show very interesting features in the process of getting funded. As expected, the task of obtaining money it is not an easy one, especially given the fact public resources have diminished from 2000 to 2006. Several factors play a role in being successful, but the analysis shows the importance of detecting the networks of collaborations for understanding how projects are funded. This is evident as at an individual level rank and disciplines alone do not seem to have a big impact. Apart from being a national coordinator, individual attributes do not explain funding success, even if full professors and some leading disciplines seem to do better than others. A high level of interdisciplinarity characterizes collaborations to Prin projects: this is probably due to the fact that fundamental research is mostly funded by Infn and Infm and take places in the big science experiments, allowing the more localised system of Prin funding to be dedicated to specific interdisciplinary applications. However, collaborations between different type of physicists and scientists from other disciplines do not produce more money, as E-I index values do not significantly increase the amount of funding. The position of institutions in the network of collaborations as well does not explain any variance. Universities which activate more Prin projects do gain overall more money, but this is not reflected at an individual level: the fact that a department is successful in getting funded does not mean that its researchers will obtain, on average, more money than the ones who work in institutions with less projects. The size of the institution itself does not seem to favour the process of getting funded: at a meso level, what counts more is the size of the fish, as being a big fish entails obtaining more funding regardless the size of pounds. Ponds do count, but

\footnotetext{
18 The distinct effects of brokerage and closure have been tested by breaking the model that inserts micro variables in two further hierarchical models: in the first one only egonetwork density is included; in the second brokerage scores are added Egonetwork density, when introduced alone, does not increase the overall explained variance much (from $18.9 \%$ to $19.4 \%$ ), it becomes negatively significant, and it does not turn astronomy negatively significant. Also, it does not reduce the gap between ranks. Brokerage scores, instead, are responsible for the largest jump in the $R^{2}$ (up to $33.8 \%$ ) and for the discussed effects on other variables. This also indicates that closure works only in combination with brokerage, as suggested by Burt (2005).
} 
Table 5

Coefficients' values.

\begin{tabular}{|c|c|c|c|c|c|c|c|c|c|c|c|c|}
\hline \multirow[t]{2}{*}{ Model } & \multicolumn{2}{|c|}{$\begin{array}{l}1 \\
\text { Unstd. Coeff. }\end{array}$} & \multicolumn{2}{|c|}{$\begin{array}{l}2 \\
\text { Unstd. Coeff. }\end{array}$} & \multicolumn{2}{|c|}{$\begin{array}{l}3 \\
\text { Unstd. Coeff. }\end{array}$} & \multicolumn{2}{|c|}{$\begin{array}{l}4 \\
\text { Unstd. Coeff. }\end{array}$} & \multicolumn{2}{|c|}{$\begin{array}{l}5 \\
\text { Unstd. Coeff. }\end{array}$} & \multicolumn{2}{|c|}{$\begin{array}{l}6 \\
\text { Unstd. Coeff. }\end{array}$} \\
\hline & $B$ & Std. error & $B$ & Std. error & $B$ & Std. error & $B$ & Std. error & $B$ & Std. error & $B$ & Std. error \\
\hline (Constant) & $10.837^{* * *}$ & .027 & $11.063^{* * *}$ & .041 & $11.057^{* * *}$ & .057 & $10.653^{* * *}$ & .080 & $10.602^{* * *}$ & .088 & $10.775^{* * *}$ & .104 \\
\hline National coordinator & $.419^{* * *}$ & .031 & $.364^{* * *}$ & .031 & $.362^{* * *}$ & .031 & $.230^{* * *}$ & .030 & $.230^{* * *}$ & .030 & $.226^{* * *}$ & .030 \\
\hline Associate & & & $-.292^{* * *}$ & .062 & $-.275^{* * *}$ & .063 & $-.181^{* *}$ & .057 & $-.182^{* *}$ & .057 & $-.169^{* *}$ & .057 \\
\hline Researcher & & & $-.489^{* * *}$ & .100 & $-.449^{* * *}$ & .101 & $-.320^{* *}$ & .092 & $-.317^{* *}$ & .092 & $-.275^{* *}$ & .092 \\
\hline Other rank & & & $-.366^{* * *}$ & .058 & -.136 & .113 & -.069 & .102 & -.009 & .111 & .007 & .111 \\
\hline Theoretical & & & & & .128 & .089 & .003 & .082 & -.008 & .082 & -.060 & .083 \\
\hline Material & & & & & .050 & .074 & -.014 & .067 & -.017 & .067 & -.011 & .066 \\
\hline Nuclear & & & & & .174 & .129 & .091 & .117 & .081 & .117 & .044 & .116 \\
\hline Astronomy & & & & & -.084 & .094 & $-.192^{* *}$ & .085 & $-.203^{* *}$ & .085 & $-.217^{* *}$ & .085 \\
\hline Earth & & & & & -.121 & .282 & -.093 & .255 & -.095 & .255 & -.106 & .252 \\
\hline Applied & & & & & $-.274^{* *}$ & .109 & $-.340^{* *}$ & .098 & $-.334^{* *}$ & .098 & $-.317^{* *}$ & .098 \\
\hline History and didactic & & & & & $-.472^{* *}$ & .214 & $-.458^{* *}$ & .194 & $-.461^{* *}$ & .194 & $-.566^{* *}$ & .193 \\
\hline Other discipline & & & & & $-.306^{* *}$ & .130 & $-.285^{* *}$ & .118 & $-.351^{* *}$ & .127 & $-.351^{* *}$ & .127 \\
\hline E-I disciplines & & & & & & & .006 & .051 & .002 & .051 & .009 & .051 \\
\hline Egonet valued density & & & & & & & $.164^{* * *}$ & .039 & $.164^{* * *}$ & .039 & $.124^{* *}$ & .040 \\
\hline Normalized broker & & & & & & & $1.702^{* * *}$ & .109 & $1.704^{* * *}$ & .109 & $1.446^{* * *}$ & .121 \\
\hline Core & & & & & & & & & .073 & .054 & .101 & .065 \\
\hline BFLP & & & & & & & & & & & .049 & .084 \\
\hline LFBP & & & & & & & & & & & $-.241^{* * *}$ & .054 \\
\hline LFLP & & & & & & & & & & & $-.166^{* *}$ & .085 \\
\hline
\end{tabular}

** $p<.05$.

$p<.001$.

in reverse effect: little fishes in big ponds seem to suffer more the competition of big fishes than little fishes in little ponds.

What really counts for individuals, in terms of obtaining more money, is being in a brokerage position, which means that the ability to change research groups and involve different people each time is a very productive strategy. Closure also has a positive impact on the average amount of funding, even if not as strong as brokerage, but the effect is positive only when brokerage and closure are included together in the model, closure alone being negatively significant. This result supports Burt's well established finding about the advantages of occupying brokerage positions and at the same time strengthening the relationship with an established research group over time (Burt, 2005). But results also suggest that the brokerage strategy might not work so well for every scientist: astronomers do not seem to take advantage of structural holes, as the values for their discipline become negatively significant when brokerage values are taken into account.

While data shows the impact of the individual position in the network, the meaning of such position in terms of what flows in the network cannot be subsumed from this kind of analysis. For example, a structural hole does not automatically entails a power of controlling information flow between different groups: while I can safely assume that closure is the result of positive relationships within a group (otherwise people would not decide to collaborate again), brokers might decide to join other groups for a large variety of reasons, which are unknown in this context. But results open up some interesting research questions in terms of community detection. The brokerage strategy impacts on the overall network structure, which shows a low level of transitivity but a good connectivity: it will be interesting to further analyse the community of physicists to find out if the network structure of collaborations to research projects is reflected in co-authorship, and if the average distance between scientists has a correlation with citations patterns.

The analysis of the meso level reinforces the need of observing structures of collaborations from different levels of interactions. The fact that big fishes obtain on average a higher amount of funding is not in itself an illuminating finding, as it simply means that the more scientists collaborate, the more money they can count on. But working in a large department seems to penalise little fishes, which are less funded, on average, than people working in small departments. This could be due to the fact that, the quality of the projects being equal, funding might be concentrated in the hands of big fishes in big departments, the rest being distributed to small departments to balance the available money across institutions. Controlling degree for the size of the department thus improves the understanding of the data, and also diminishes the effect of micro network variables, showing that while the position of individuals in the network is the most important element in predicting the amount of funding, the size of institutions does have an overarching influence on people.

Obviously there are some limits to the research presented here. First of all, rank is recorded only in 2006: we do not know if people get funded because of their rank, or whether they get promoted because they obtain funding. Therefore results of the regression model should be considered with care, as it is not possible to test the causal effect of rank over funding. The low level of $R^{2}$ only means that rank in itself is not decisive. Secondly, the size of the ponds is not defined by a proper empirical network measure: I could not map relationships between institutions other than the macro level of interactions for research projects. Therefore the decision of using the number of physicists appointed in every University only gives a proxy measure of the potential pools of available local contacts: this is still relevant information, as the size of departments is considered an important criterion of evaluation from the public sector, not only for Prin projects, but for a whole range of funding. The same limit applies to the micro level of interaction. Here I only detect collaborations to specific research projects, cutting out all the other forms of interactions which occur between scientists. However, the reciprocal selection of scientific partners can be an indicator not only of a concrete relationship between researchers (people must know each other to decide to collaborate), but also of mutual respect: the decision of committing to a two year project together has to be the result of previous meaningful contacts, and of reciprocal awareness of each other's work. Another limit consists in the fact that data only refer to the decade from 1997 to 2006. The unavailability of information for previous years means that we cannot detect the previous network of collaborations, which might have shown different structure and mechanisms. Also, data on unsuccessful research projects are not available; therefore I could not compare the network of 
funded collaborations with the one of rejected projects. This is a serious limit if a statistical analysis of the network dynamics is to be performed.

Finally, as usual in social network research, results are only valid for the specific field of Prin funding to physics research projects in Italy. Data cannot be generalized to other sectors, other funding lines, or other countries. What is extremely valuable is the observation of specific network mechanisms that seem to play a determinant role in many kinds of networks. Here, as observed for different contexts and different organizations (Burt, 2005), the combination of brokerage and closure represents the best strategy to obtain funding and succeed in developing innovations. This is partially in contrast with Lazega et al.'s results (2008), where the position of the laboratory in the network of inter-organizational exchanges counted more than the position of individuals in the network of the élite. In my case, results show that working in a core institution does not increase the average amount of funding. Also, the size of the pond seems to only favour already successful researchers, penalising the one who collaborate less. But the size of the pond diminishes the effects of being in a brokerage position, suggesting the importance of adopting Lazega et al.'s multilevel approach as it enriches the analysis of the data controlling at the same time for the effects of micro and macro levels over the work of scientists. Given the fact the inter-individual and interorganizational networks are constructed differently from the ones of Lazega et al., and they refer to different contexts of scientific production, direct comparison of results is not possible, but the method they propose works in this context too, and it calls for more similar studies.

\section{Conclusions}

In this paper I analyse the structure of collaboration to physics research projects in Italy using social network analysis. The theoretical framework insists on the importance of the connections scientists make during their work over the classic variables describing individual and organizational features. The study is important as it shows how, more than rank, disciplinary or institutional affiliation, it is the position of researchers in the overall structure of collaboration that counts in terms of getting funded. Results add credibility to the stream in sociology of science that claims the importance of detecting scientific communities approaching them not only at an individual level or at a macro level, but taking into account the micro level of interactions and the meso level of reciprocal influence between networks of collaborations and institutional affiliation. Moreover, it looks at scientific prestige not from the classic point of view of publications, but from the perspective of obtaining funding for research. Together with interesting results, the paper also opens further research questions which are worth investigating.

First, it will be interesting to analyse the narrative description of research projects that is included in the pdf files: every projects states the goal of the research, the expected production of innovative results in its scientific area, the list of verifiable criteria through which results are going to be validate by the scientific community (provisional conference presentations, publications, patents, training initiatives, and the like), and the specific program of work for every single unit of the collaboration. Qualitative analysis of this material will allow to link the scientific content (and its claimed innovative aspects) of every project to its position in the network: so far I have analysed the transposed matrices of people and institutions, but the same two mode "people by project" network can be transpose as a project by project matrix, where it will be interesting to see the disposition of research topics in the structure of collaboration.
Second, it would be interesting to interview physicists in different positions in the network, for example people with high, medium and low brokerage scores, to investigate the process they activate when deciding to set up or participate to Prin projects: how they chose the topic, how they select co-participants, how they assign tasks to different units, how they allocate the human, technical and economic resources, and the multiplex nature of relationships they establish with colleagues. This could shine a light on hidden dyadic and structural mechanisms that the simple detection of collaboration ties does not allow to explore.

Third, the longitudinal two mode format of the data poses some challenges to the extension of the analysis to statistical modelling of networks over time. It will be interesting to combine Exponential Random Graph Models (ERGM) and actor-based models to simulate the decision of scientists to select a research project to which participate, and to modify the composition of research groups they decide to collaborate with year by year (taking into account the fact that projects last for two years, therefore the overall network is observed in 5 different time points over the 10 years). Although of great value, the dynamic analysis of this dataset cannot be easily performed, because for every year there is a completely different list of actors and projects. Actors funded in year one cannot be funded in year two, they might not be funded in year 3 (unsuccessful bid) and then get funded again in year 4 . This means that each year has a completely different set of actors, which violate one of the requirements for Siena modelling.

Finally, an already ongoing project aims to compare the structure of collaboration to research project in physics with the same type of data collected for philosophy. Prin data for philosophy have been so far only partially collected (from 2000 to 2006): once the data collection is completed, it will be possible to analyse the structure of philosophy in similar terms and compare the mechanisms that regulate the two networks.

\section{Acknowledgements}

I would like to thank Mark Tranmer, Johan Koskinen and Martin Everett for the helpful discussions and advices, and the two anonymous reviewers for the useful comments and suggestions.

\section{References}

Barnes, B., Bloor, D., 1982. Relativism, rationalism and sociology of knowledge. In: Hollis, M., Lukes, S. (Eds.), Rationality and Relativism. Blackwell, Oxford.

Bellotti, E., 2011. The social processes of production and validation of knowledge in particle physics: preliminary theoretical and methodological observations. Procedia Social and Behavioral Sciences 10, 148-159.

Bellotti, E., 2008. La struttura del campo scientifico: vincoli e risorse della produzione di conoscenza. In: Bellotti, E., Beltrame, L., Volontè, P. (Eds.), Il campo sociale della fisica particellare in Italia. Uno studio sociologico. Bolzano University Press, Bolzano.

Bellotti, E., Beltrame, L., Volontè, P., 2008. Il campo sociale della fisica particellare in Italia. Uno studio sociologico. Bolzano University Press, Bolzano.

Beltrame, L., 2008. La struttura del campo scientifico: una geografia delle traiettorie dei fisici delle particelle. In: Bellotti, E., Beltrame, L., Volontè, P. (Eds.), I campo sociale della fisica particellare in Italia. Uno studio sociologico. Bolzano University Press, Bolzano.

Bourdieu, P., 2004. An Invitation to Reflexive Sociology. Polity Press, Cambridge.

Breiger, R., 1974. The duality of persons and groups. Social Forces 53, 181-190.

Burt, R.S., 1978/79. Stratification and prestige among elite experts in methodological and mathematical sociology circa 1975 . Social Networks 1, 105-158.

Burt, R.S., 2005. Brokerage and Closure. An Introduction to Social Capital. Oxford University Press, Oxford.

Callon, M., 2001. Les méthodes d'analyse des grands nombres peuvent-elles contribuer à l'enrichissement de la sociologie du travail? In: Pouchet, A. (Ed.) Sociologies du travail: quarante ans après. Elsevier, Paris.

Cambrosio, A., Keating, P., Mogoutov, A., 2004. Mapping collaborative work and innovation in biomedicine. Social Studies of Science 34, 325-364.

Collins, H., 1985. Changing Order. Replication and Induction in Scientific Practice The University of Chicago Press, Chicago.

Crane, D., 1972. Invisible Colleges. Chicago University Press, Chicago.

de Solla Price, D.J., 1963. Little Science, Big Science. Columbia University Press, New York 
Fararo, T.J., Doreian, P., 1984. Tripartite structural analysis: generalizing the Breiger-Wilson formalism. Social Networks 6, 141-175.

Gilbert, G.N., Mulkay, M., 1984. Opening Pandora's Box: A Sociological Analysis of Scientists' Discourse. Cambridge University Press, Cambridge.

Hedström, P., Sandell, R., Stern, Ch., 2000. Mesolevel networks and the diffusion of social movements: the case of the Swedish social democratic party. American Journal of Sociology 106, 145-172.

Hummon, N.P., Carley, K., 1993. Social networks as normal science. Social Networks $15,71-106$.

Hummon, N.P., Doreian, P., 1989. Connectivity in a citation network: the development of DNA theory. Social Networks 11, 39-63.

Ippolito, F., Simen, F., 1974. La questione energetica. Dieci anni perduti 1963/1973. Feltrinelli, Milano.

Knorr-Cetina, K., 1992. The couch, the cathedral and the laboratory: on the relationship between experiment and laboratory in science. In: Pickering, A. (Ed.), Science as Practice and Culture. University of Chicago Press, Chicago.

Krackhardt, D., Stern, R.N., 1988. Informal networks and organizational crises: an experimental simulation. Social Psychology Quarterly 51 (2), 123-140.

Kuhn, T.S., 1962. The Structure of Scientific Revolutions. University of Chicago Press, Chicago.

Latour, B., 1987. Science in Action: How to Follow Scientists and Engineers through Society. Harvard University Press, Cambridge, MA.

Latour, B., 2005. Reassembling the Social: An Introduction to Actor-Network-Theory. Oxford University Press, Oxford.
Lazega, E., Jourda, M.T., Mounier, L., Stofer, R., 2008. Catching up with big fish in the big pond? Multi-level network analysis through linked design. Social Networks 30, 157-176.

Leenders, T.Th.A.J., 2002. Modeling social influence through network autocorrelation: constructing the weight matrix. Social Networks 24 (1), 21-47.

Liberman, S., Wolf, K.B., 1998. Bonding number in scientific disciplines. Social Networks 20, 239-246.

Lievrouw, L.A., Rogers, E.M., Lowe, C.U., Nadel, E., 1987. Triangulation as a research strategy for identifying invisible colleges among biomedical scientists. Social Networks 9, 217-248.

Merton, R.K., 1949. Social Theory and Social Structure. The Free Press, New York.

Parcel, T.L., Kaufman, R.L., Leeann, J., 1991. Going up the ladder: multiplicity sampling to create linked macro-to-micro organizational samples. In: Marsden, P. (Ed.), Sociological Methodology. Basil Blackwell, Oxford.

Volontè, P., 2008. Il campo sociale della fisica delle particelle in Italia. In: Bellotti, E., Beltrame, L., Volontè, P. (Eds.), Il campo sociale della fisica particellare in Italia. Uno studio sociologico. Bolzano University Press, Bolzano.

Whittle, A., Spicer, A., 2008. Is actor network theory critique? Organization Studies 29, 611-629.

Wilson, T.P., 1982. Relational networks: an extension of sociometric concepts. Social Networks 4, 105-116. 